\title{
Effect of the Treatment of the Olive Tree (Olea europaea L.) on the Phenolic Content and Antioxidant Properties in Olive Fruits
}

\author{
Gracia Patricia Blanch ${ }^{1}$, Gema Flores ${ }^{1}$, Maria C. Gómez-Jiménez ${ }^{2}$, Maria Luisa Ruiz del Castillo ${ }^{1, *}$ \\ ${ }^{1}$ Instituto de Ciencia y Tecnología de Alimentos y Nutrición. Consejo Superior de Investigaciones Científicas (ICTAN-CSIC), \\ Juan de la Cierva 3, 28006 Madrid \\ ${ }^{2}$ Departamento de Biología Vegetal, Ecología y Ciencias de la Tierra, Universidad de Extremadura, \\ Avda/ de Elvas, s/n, 06006, Badajoz \\ *Corresponding author: mruiz@ictan.csic.es
}

\begin{abstract}
We here investigate the effects of the application of methyl jasmonate to olive trees on antioxidant composition of olive fruits. Two cultivars (ie, Arbequina and Picual) were evaluated in our study. As a result, the total phenol content increased significantly with the treatment in Arbequina (from 155.89 to $434.22 \mathrm{mg}$ gallic acid $\mathrm{kg}^{-1}$ ) whereas decreases were observed in Picual (from 338.27 to $127.71 \mathrm{mg}$ gallic acid $\mathrm{kg}^{-1}$ ). Similarly, decreases in phenolic acid content were measured in Arbequina whilst no effect was observed in Picual olives. However, the contents of oleuropein and hydroxytyrosol did not increase with the pre-harvest methyl jasmonate for both Arbequina and Picual. Also for both cultivars the treatment of the olive trees increased the free radical scavenging activity of the olive fruits $\left(\mathrm{IC}_{50}\right.$ from 514.36 to $1125.46 \mu \mathrm{g} / \mathrm{mL}$ in Arbequina and from 611.98 to 114.55 $\mu \mathrm{g} / \mathrm{mL}$ in Picual). The results here found are deeply discussed.
\end{abstract}

Keywords: olive fruit, olive tree, methyl jasmonate, antioxidant, pre-harvest treatment, phenolics, quality

Cite This Article: Gracia Patricia Blanch, Gema Flores, Maria C. Gómez-Jiménez, and Maria Luisa Ruiz del Castillo, "Effect of the Treatment of the Olive Tree (Olea europaea L.) on the Phenolic Content and Antioxidant Properties in Olive Fruits." Journal of Food and Nutrition Research, vol. 6, no. 1 (2017): 49-55. doi: 10.12691/jfnr-6-1-8.

\section{Introduction}

Olive tree (Olea europaea L.) is very popular in the Mediterranean area because of its fruits and oil. Both of them are worldwide known by their beneficial health properties [1]. These benefits are in part associated with the high amounts of nutritionally relevant constituents, mainly mono-unsaturated fatty acids, but also certain minor components such as polyphenols. Among polyphenols, oleuropein and related compounds are generally the most predominant phenolic compounds in olive cultivar [2,3]. Oleuropein is a secoiridoid compound present in all olive tree derivatives (olive oil, olive fruit, olive mill wastewater and pomace). The beneficial effects on human health of oleuropein and some related compounds such as hydroxytyrosol have been widely reported. In particular, they have been described to possess antioxidative [4], antimicrobial [5], antiviral [6], anti-inflammatory [7], cardioprotective [8] and neuroprotective [9] properties. Other important phenolics in olives are phenolic acids. Although their occurrence is minor, their therapeutic effect is equally remarkable. Phenolics acids have demonstrated protection against a range of diseases, including cancer, heart diseases and diabetes [10,11]. These positive effects have been mainly attributed to their antioxidant properties.
Nowadays the awareness of the relationship between diet and health has led to a search for functional foods to prevent naturally nutrition-related diseases. In this regard, it has been demonstrated that the chemical elicitation of plant foods is an interesting technique to develop functional foods by means of the enrichment in bioactive compounds.

Various elicitors have been reported to induce bioactive compound production in plant foods; among them methyl jasmonate (MJ) is considered to be particularly effective.

In the past few years we have focused our research on the development of plant foods enriched in phenolics by using the exposition of the food to chemical elicitors. We have mainly studied MJ effects on berries and potato $[12,13,14]$. More recently we have also investigated MJ effect on fatty acids and phenolic acids in olive fruits [15]. These studies were mostly centered on the postharvest treatment which implies the application of the elicitor over the food immediately after harvest. However, occasional works have also been accomplished on the pre-harvest elicitation effect, in other words application of the elicitor to the plant before harvest instead of to the food. Besides, pre-harvest treatments possess the addition advantage of protecting the plant from chilling injuries and diseases [16].

The goal of this work was to investigate the effect of the pre-harvest MJ application on the phenolic fraction of olive fruits. For that purpose, we sprayed MJ to olive trees 
during the ripening process of the olive fruits. Our final intention was to obtain olive fruits enriched in phenolic compounds with antioxidant properties. We evaluated MJ effects on the total phenolic content (TPC), free radical scavenging assay and the contents of some relevant phenolic compounds (ie, oleuropein, hydroxytyrosol and phenolic acids). The results were compared with those obtained from olive fruits picked from untreated olive trees, which were used as controls. Two olive cultivars (Arbequina and Picual) were included in our study to consider the varietal influence on $\mathrm{MJ}$ effect.

\section{Materials and Method}

\subsection{Samples and Chemicals}

HPLC-grade $\mathrm{MeOH}$ was supplied by VWR Inc. (Bridgeport, PA, USA). Ultrapure water was collected from a purification system (Millipore Milford, MA, USA). Acetic acid was obtained from Probus (Barcelona, Madrid). MJ was purchased from Sigma-Aldrich (Steinheim, Germany). Sodium carbonate and Folin-Ciocalteu reagent were supplied by Merck (Darmstadt, Germany). Oleuropein, hyrdroxytyrosol, 1,1-diphenyl-2-picrylhydrazil (DPPH) and phenolic acid standards (i.e., gallic, vanillic, $p$-coumaric, caffeic, chlorogenic, and ferulic acids) were acquired by SigmaAldrich (Steinheim, Germany). Olive fruits (Arbequina and Picual cultivars) were hand-picked from the trees in November and December 2016 in the University of Extremadura (Badajoz, Spain). Only undamaged fruits without any kind of infection of physical injury were selected for the experiments. All fruits exhibited the same maturity stage. After harvesting, the olive fruits, from both untreated and treated trees, were immediately frozen at $80^{\circ} \mathrm{C}$ up to the analysis, as explained below.

\subsection{Plan Material and MJ Treatment}

Twenty-year-old olive tree (Olea europaea L.) of two cultivars, Arbequina and Picual, grown under trip irrigation and fertirrigation (irrigation with suitable fertilizers in the solution) in the same orchard near Badajoz (Spain) under the same agronomical and environmental condition were studied.

Treatments were performed on olive trees (5 per treatment) of Arbequina and Picual cultivars. Two branches per tree were selected for experiments for uniform size and fruit load. For each treatment, 5 branches (1 branch for tree) were sprayed with a solution of $500 \mathrm{mg} / \mathrm{L}$ of $\mathrm{MJ}$ in ethanol and the other 5 branches ( 1 branch for tree) were not sprayed at all to be used as controls. A $500 \mathrm{~mL}$ volume of MJ solution was applied per branch at the time of harvest. To avoid contamination during spraying, at least one guard tree was used to separate each of the test trees, and the trees were sprayed with the solutions only when there was a weak and no wind. For the purposes of this study, olive fruit samples of each cultivar were collected from each tree (300 fruits) on days 3 and 6 after treatments. A total of 1500 fruits were collected for each treatment and time point of each cultivar, and were immediately frozen in liquid nitrogen and stored at $-80^{\circ} \mathrm{C}$ until analysis.

\subsection{Analysis of Phenolic Compounds}

\subsubsection{Extraction}

Phenolic composition was examined in untreated and MJ treated olive fruits. The extraction was performed on the basis of the method described in the literature [17] with slight modifications. First, a $60 \mathrm{~mL}$-volume of 80:20 (v/v) methanol:water was added to a 5 g-weight of destones olive sample. Then, the mixture was homogenized by using and Ultraturrax (IKA, Sigma-Aldrich, Madrid, Spain) and subsequently centrifuged at $1500 \mathrm{rpm}$ for 10 min at room temperature. The supernatant was filtered through filter paper. An additional $60 \mathrm{~mL}$ of methanol:water was added to the extract, which was reextracted. After that, $30 \mathrm{~mL}$ of hexane was added to the resulting extract to eliminate the remaining oil. Once discharged the hexane layer, the combined methanolic extracts were collected, filtered through Whatman No. 1 filter paper and analyzed by HPLC as detailed below. Extractions of each single sample including controls and olives treated with MJ were accomplished in duplicate. As detailed below, the extracts obtained were used for the free radical scavenging assay and to determine TPC and contents of oleuropein, hydroxytyrosol and phenolic acids.

\subsubsection{Determination of TPC}

A Beckman Coulter DU-800 spectrophotometer (Barcelona, Spain) was used to perform the measurements. The determination of TPC was carried out by following the method described elsewhere [18]. Basically, the method is based on the oxidation of the hydroxyl groups of phenols in basic media by the Folin-Ciocalteu reagent. A $0.1-\mathrm{mL}$ volume of the extract, $0.5 \mathrm{~mL}$ of Folin-Ciocalteu reagent and $10 \mathrm{~mL}$ of sodium carbonate solution $(75 \mathrm{~g} / \mathrm{L})$ were mixed, and the volume was made up to $25 \mathrm{~mL}$ with distilled water. After $1 \mathrm{~h}$, the absorbance was measured at $750 \mathrm{~nm}$ against a blank prepared in the same way but without adding the reagent. Gallic acid was used as the standard to prepare the calibration curve. The results were expressed as milligrams of gallic acid equivalents per $\mathrm{kg}$ of olive fruit. Analyses were performed in triplicate.

\subsubsection{1,1-Diphenyl-2-picrylhydrazyl Free Radical (DPPH*) Scavenging Assay}

The same equipment as that used for TPC was used for DPPH measurements. The ability of the extracts to scavenge $\mathrm{DPPH}^{*}$ radicals was performed according to a slight modification of the method elsewhere developed [19]. Each extract was further diluted to final concentrations of $15.6,62.5,125,250$ and $500 \mu \mathrm{g} / \mathrm{mL}$ before being transferred to a 96-well microliter plate. Each extract solution, before adding DPPH, was used as a blank. Each well contained $50 \mu \mathrm{L}$ aliquot of the sample and $150 \mu \mathrm{L}$ of DPPH $(400 \mu \mathrm{M})$. Decrease of absorbance, with respect to DPPH solution measured immediately, was monitored at $517 \mathrm{~nm}$ after $30 \mathrm{~min}$ of incubation at $37^{\circ} \mathrm{C}$. The percentage inhibition of the DPPH by each dilution of samples was calculated considering the percentage of the steady DPPH in solution after reaction. Results were expressed as the concentration of extracts that gives rise to a $50 \%$ reduction in the DPPH. The experiments were performed in triplicate. 


\subsubsection{Determination of Oleuropein and Hydroxytyrosol}

A Konik-Tech model 560 (Barcelona, Spain) liquid chromatograph fitted with a manual injection valve (model 7725i, Konik-Tech, Barcelona, Spain) and having a $20 \mu \mathrm{l}$ sample loop was used for the analyses. The separation was accomplished on a ODS reverse phase (C18) column (250 $\mathrm{nm} \times 4.6 \mathrm{~mm}$ i.d., $5 \mu \mathrm{m}$ particle size, ACE, Madrid, Spain). A mixture of water/acetic acid (95/5, v/v) and methanol were used as solvents A and B, respectively and the flow rate was $1 \mathrm{~mL} / \mathrm{min}$. A linear gradient was programmed as follows: initial composition 95/5\% A/B, 85/15 A/B at 3 min, $80 / 20 \mathrm{~A} / \mathrm{B}$ at $13 \mathrm{~min}, 75 / 25 \mathrm{~A} / \mathrm{B}$ at $25 \mathrm{~min}, 70 / 30 \mathrm{~A} / \mathrm{B}$ at $35 \mathrm{~min}, 65 / 35 \mathrm{~A} / \mathrm{B}$ at $40 \mathrm{~min}, 60 / 40 \mathrm{~A} / \mathrm{B}$ at $45 \mathrm{~min}, 55 / 45$ $\mathrm{A} / \mathrm{B}$ at $47 \mathrm{~min}, 53 / 47 \mathrm{~A} / \mathrm{B}$ at $50 \mathrm{~min}, 52 / 48 \mathrm{~A} / \mathrm{B}$ at $60 \mathrm{~min}$, $50 / 50 \mathrm{~A} / \mathrm{B}$ at $64 \mathrm{~min}, 50 / 50 \mathrm{~A} / \mathrm{B}$ at $70 \mathrm{~min}, 95 / 5 \mathrm{~A} / \mathrm{B}$ at $75 \mathrm{~min}$. Chromatograms were recorded at $280 \mathrm{~nm}$. Blanks between consecutive runs were performed to assure the washing of the equipment. Three HPLC runs were performed for each single extract. Stock solutions of the standard compounds were prepared in $70 \%(\mathrm{v} / \mathrm{v})$ methanol to final concentration of $1 \mathrm{mg} / \mathrm{mL}$. Each stock solution was further diluted to obtain six concentrations of the standard. Calibration curves of the standards were established on six data points, and each standard dilution was injected in triplicate. Peak areas for the extracts and standards were integrated by use of Konikrom Plus (KNK-725-240). Analyses were performed in triplicate.

\subsubsection{Determination of Phenolic Acids}

The equipment and method used were the same as the one described above for oleuropein and hydroxytyrosol. Chromatograms were recorded at two different wavelengths. Gallic acid and vanillic acid were detected at $280 \mathrm{~nm}$ whereas caffeic, $p$-coumaric, ferulic and chlorogenic acids were measured at $320 \mathrm{~nm}$. Blanks between consecutive runs were performed to assure the washing of the equipment. Three HPLC runs were performed for each single extract. Stock solutions of the standard compounds were prepared in $70 \%$ (v/v) methanol to final concentration of $1 \mathrm{mg} / \mathrm{mL}$. Each stock solution was further diluted to obtain six concentrations of the standard. Calibration curves of the standards were established on six data points, and each standard dilution was injected in triplicate. Peak areas for the extracts and standards were integrated by use of Konikrom Plus (KNK-725-240). Analyses were performed in triplicate

\subsection{Statistical Analysis}

The results are presented as the average of the all values obtained and standard deviation $( \pm$ SD). The two varieties Arbequina and Picual are included in the statistical analysis. The data were analyzed using one-way analysis of variance (ANOVA), and differences were considered significant at $p<0.05$.

\section{Results and Discussion}

\subsection{TPC and DPPH Activity}

Table 1 represents the TPC, expressed as mg gallic acid $\mathrm{kg}^{-1}$ in olives fruits picked from olive trees untreated (control) and treated with MJ. Olive samples were collected on two different days, day 3 and day 6 after treatment. Data provided by two different varieties, Arbequina and Picual, were included in our study to evaluate the varietal influence on the MJ effect. Statistical analysis was carried out between control and treated samples and between Arbequina and Picual varieties. Data on days 3 and 6 were not statistically compared.

From Table 1, TPCs ranged from 127.71 to $472.23 \mathrm{mg}$ gallic acid $\mathrm{kg}^{-1}$, which is in accordance with data published in olives in the literature [20]. By comparing controls from Arbequina and Picual, differences between cultivars were found. In particular, Picual exhibited significantly $(p<0.05)$ higher TPCs than Arbequina on both days 3 and 6 . This observation supports bibliographic reports which have already described varietal differences in the phenolic content in olives [21].

It is also interesting to note that, although data on days 3 and 6 were not statistically compared, the decline of the composition of TPC overtime in both Arbequina and Picual varieties was apparent. Particularly, TPC on day 3 were $265.61 \mathrm{mg}$ gallic acid kg-1 in Arbequina vs $472.23 \mathrm{mg}$ gallic acid $\mathrm{kg}^{-1}$ in Picual. In the same way $155.89 \mathrm{mg}$ gallic acid kg-1 were measured in Arbequina vs 338.27 in Picual on day 6. Decrease in TPC as ripening progresses has been reported in the literature [22]. These values might indicate that olives on day 6 were picked close to overripe and, therefore, day 3 would be more recommendable as a picking day.

As far as the MJ treatment effect is concerned, different responses to $\mathrm{MJ}$ were observed in olives according to the variety. As seen, TPC increased significantly $(p<0.05)$ in Arbequina samples after the treatment on both harvesting days (ie, day 3 and 6). By contrast, for Picual the MJ treatment resulted in a significant $(p<0.05)$ decrease of TPC, particularly on day 6 (ie, from 338.27 to $127.71 \mathrm{mg}$ gallic acid $\mathrm{kg}^{-1}$ ). MJ is a phytohormone that regulates relevant metabolic processes and may bring about opposite effects on polyphenol metabolism in plant foods. On the one hand, MJ is involved in the ethylene production in such a way that accelerates the ripening process, which, in turn, conducts to the drop of the polyphenol content. On the other hand, it is already known the promoting MJ effect on phenyl-alanine lyase (PAL), which is the first enzyme regulating the bioformation of phenolics through phenylpropanoid pathway. In particular, PAL catalyzes the formation of cinnamic acid from phenylalanine and then cinnamic acid is transformed in naringenin, which is subsequently converted into different flavonoids including phenolic acids [23,24]. In view of our results, the activation of $\mathrm{PAL}$ as a result of the preharvest MJ application to olive trees prevailed over ethylene production for Arbequina samples whereas the stimulation of ripening process was clearly predominant over the induction of the polyphenol biosynthesis by PAL activation for Picual olives. This finding is in accordance with metabolic differences previously observed in Arbequina and Picual. In particular, both cultivars have shown different ripening behavior. Whereas Arbequina does not continue to ripen after harvest, Picual olives are capable of ripening during the postharvest period (data submitted for publication). The different response of both cultivars to MJ in terms of TPC suggests higher susceptibility of Picual to the ethylene production. 
Table 1. Total phenol content ( $\mathrm{mg}$ gallic acid $\left.\mathrm{kg}^{-1}\right)$ in olive fruits from Arbequina and Picual olive trees (Olea europaea L.) untreatedcontrol and treated with MJ. Olive samples were picked on days 3 and 6 after $M J$ treatment

\begin{tabular}{|c|c|c|}
\hline $\begin{array}{l}\text { TOTAL PHENOLS } \\
\left(\text { mg gallic acid kg }^{-1}\right)\end{array}$ & ARBEQUINA & PICUAL \\
\hline \multicolumn{3}{|l|}{ DAY 3} \\
\hline CONTROL & $265.61 \pm 0.23 \mathrm{Aa}$ & $472.23 \pm 0.65 \mathrm{Ba}$ \\
\hline MJ TREATED & $430.55 \pm 0.35 \mathrm{Ab}$ & $380.10 \pm 0.54 \mathrm{Bb}$ \\
\hline \multicolumn{3}{|l|}{ DAY 6} \\
\hline CONTROL & $155.89 \pm 0.38 \mathrm{Aa}$ & $338.27 \pm 0.55 \mathrm{Ba}$ \\
\hline MJ TREATED & $434.22 \pm 0.46 \mathrm{Ab}$ & $127.71 \pm 0.68 \mathrm{Bb}$ \\
\hline
\end{tabular}

Data are presented as means $(n=3) \pm \mathrm{SD}$, where $n$ refers to three independent samples.

Different upper-case letters in the same row in control samples between cultivars indicate differences at $p<0.05$

Different lower-case letters in the same column between control and MJ treated samples within the same cultivar indicate differences at $p<0.05$.

Table 2. DPPH scavenging activity expressed as $\mathrm{IC}_{50}(\mu \mathrm{g} / \mathrm{mL})$ of olive fruits from Arbequina and Picual olive trees (Olea europaea L.) treated with MJ. Olive samples were picked on days 3 and 6 after MJ application

\begin{tabular}{|l|c|c|}
\hline IC50 $(\boldsymbol{\mu g} / \mathbf{m L})$ & ARBEQUINA & PICUAL \\
\hline DAY 3 & $514.36 \pm 1.02 \mathrm{Aa}$ & $539.12 \pm 1.13 \mathrm{Aa}$ \\
\hline CONTROL & $1125.46 \pm 0.86 \mathrm{Ab}$ & $638.57 \pm 0.92 \mathrm{Bb}$ \\
\hline MJ TREATED & $585.02 \pm 0.78 \mathrm{Aa}$ & $611.98 \pm 0.96 \mathrm{Aa}$ \\
\hline DAY 6 & $343.67 \pm 0.89 \mathrm{Ab}$ & $1146.55 \pm 0.74 \mathrm{Bb}$ \\
\hline CONTROL
\end{tabular}

Data are presented as means $(n=3) \pm \mathrm{SD}$, where $n$ refers to three independent samples.

Different upper-case letters in the same row in control samples between cultivars indicate differences at $p<0.05$

Different lower-case letters in the same column between control and MJ treated samples within the same cultivar indicate differences at $p<0.05$.

Table 2 represents the $\mathrm{IC}_{50}$ values, expressed as $\mu \mathrm{g} / \mathrm{mL}$, of olive fruits from Arbequina and Picual olive trees (Olea europaea L.) treated with MJ. Data from olives picked on days 3 and 6 after pre-harvest MJ application were included in the table, although they were not in the statistical comparison. As seen in the table, $\mathrm{IC}_{50}$ measured in control olives were statistically similar $(p>0.05)$ for both varieties. In particular values of 514.36 and 539.12 $\mu \mathrm{g} / \mathrm{mL}$ were obtained on day 3 and 585.02 and 611.98 $\mu \mathrm{g} / \mathrm{mL}$ on day 6 for Arbequina and Picual respectively. Therefore, the radical scavenging activity was not found to depend on the cultivar.

Regarding the $\mathrm{MJ}$ effect, differences in $\mathrm{IC}_{50}$ values were significant $(p<0.05)$ in MJ treated samples as compared with controls for both varieties. Specifically, Arbequina olives exhibited a significant $(p<0.05)$ increase in the radical scavenging activity after pre-harvest MJ application on day $3(1125.46 v s 514.36 \mu \mathrm{g} / \mathrm{mL})$. By contrast, the radical scavenging activity declined significantly $(p>0.05)$ in MJ treated olives on day 6 (343.67 vs $585.02 \mu \mathrm{g} / \mathrm{mL})$. However, Picual olives exerted a significant $(p<0.05)$ increase in the radical scavenging activity on both days 3 and 6 as a result of the exposition of olive trees to MJ, although this increase was more pronounced on day 6 $(1146.55 \mu \mathrm{g} / \mathrm{mL}$ in $\mathrm{MJ}$ treated olives vs $611.98 \mu \mathrm{g} / \mathrm{mL}$ in controls). These results reflect, once more, the different metabolic processes during the ripening process for both Arbequina and Picual cultivars.

A possible correlation between TPC and the DPPH activity was investigated. As a result, the linear regressions corresponding to TPC and DPPH data obtained were $\mathrm{y}=0.6467 \mathrm{x}+434.17\left(\mathrm{r}^{2}=0.0674\right)$ for Arbequina and $\mathrm{y}=-1.8353 \mathrm{x}+1338.9\left(\mathrm{r}^{2}=0.9246\right)$ for Picual. As observed, a linear correlation between TPC and DPPH activity could not be established either for Arbequina or Picual. This lack of linearity was more visible for Picual olives since the effectiveness of pre-harvest MJ treatment in terms of DPPH activity (see Table 2) was noteworthy despite the decrease in TPC in MJ treated olives (see Table 1). The discrepancy between TPC and DPPH activity suggests the presence of some potent antioxidants other than those here studied in MJ treated olives whose content is low enough not to affect TPC. It is necessary to bear in mind that the biological activity is not directly related to concentration. Actually, some minor constituents are usually described as particularly active compounds in a number of areas [25]. Structural elucidation studies in combination with free radical scavenging assays are currently scheduled to get an insight of structure-activity relation in olive phenolics other than those here considered.

\subsection{Oleuropein and Hydroxytyrosol}

Table 3 depicts the oleuropein content expressed as $\mathrm{mg} \mathrm{kg}^{-1}$ weight in olive fruits from Arbequina and Picual olive trees (Olea europaea L.) untreated-control and treated with MJ. Data obtained from fruits picked on days 3 and 6 after the treatment are also represented although, as already mentioned, they were not considered in the statistical study. Oleuropein contents here found are in general lower than those reported in olive fruits by other authors [20]. This can be due to a number of factors such as geographical aspects, agronomic conditions, among others. By comparing controls of Arbequina and Picual, the oleuropein content was statistically $(p>0.05)$ similar in both varieties on day 3 (129.96 and $122.59 \mathrm{mg} \mathrm{kg}^{-1}$ for Arbequina and Picual respectively). However, measurements on day 6 exhibited higher oleuropein content in Picual than in Arbequina. Besides, higher contents of oleuropein on day 6 than on day 3 were evident for both cultivars (ie, $220.45 \mathrm{mg} \mathrm{kg}^{-1}$ and $348 \mathrm{mg} \mathrm{kg}^{-1}$ for Arbequina and Picual, respectively). Bibliographic reports have already described higher contents of oleuropein during the final stages of olive fruit ripening [26]. This supports the above mentioned observation that the day 6 represents the final of the olive ripening process, close to overripe. It is also interesting that, despite oleuropein is a major phenolic in olive, the increase of the oleuropein content on day 6 does not correlate with the drop in TPC on that same day. This fact can be attributed to relevant contributions of phenolics other than oleuropein to TPC. These authors have also reported no direct relation between the trend of oleuropein and TPC during the fruit ripening process [26]. In particular, these authors have found that during the first stages of olive ripening process, oleuropein content starts increasing whereas no change in TPC is observed. Nevertheless, they always found coincidence between enzymatic activity and oleuropein concentration. 
Table 3. Oleuropein contents (expressed as $\mathrm{mg} \mathrm{kg}^{-1}$ weight $\pm \mathrm{SD}$ ) in olive fruits from Arbequina and Picual olive trees (Olea europaea $\mathrm{L}$. ) treated with MJ. Data from olive samples picked on days 3 and 6 after MJ application are included

\begin{tabular}{|c|c|c|c|c|}
\hline \multirow{2}{*}{$\begin{array}{c}\text { OLEUROPEIN CONTENT } \\
\left(\mathbf{m g ~ k g}^{-1)}\right.\end{array}$} & \multicolumn{2}{|c|}{ ARBEQUINA } & \multicolumn{2}{c|}{ PICUAL } \\
\cline { 2 - 5 } & CONTROL & MJ TREATED & CONTROL & MJ TREATED \\
\hline DAY 3 & $129.96 \pm 1.52 \mathrm{Aa}$ & $121.00 \pm 1.93 \mathrm{Aa}$ & $122.59 \pm 0.96 \mathrm{Aa}$ & $139.26 \pm 1.76 \mathrm{Aa}$ \\
\hline DAY 6 & $220.45 \pm 2.05 \mathrm{Aa}$ & $159.15 \pm 1.35 \mathrm{Ab}$ & $348.00 \pm 1.83 \mathrm{Ba}$ & $576.38 \pm 1.45 \mathrm{Bb}$ \\
\hline
\end{tabular}

Data are presented as means $(n=3) \pm \mathrm{SD}$, where $n$ refers to three independent samples.

Different upper-case letters in the same row in control samples between cultivars indicate differences at $p<0.05$

Different lower-case letters in the same row between control and MJ treated samples within the same cultivar indicate differences at $p<0.05$

Table 4. Hydroxytyrosol contents (expressed as $\mathrm{mg} \mathrm{kg}^{-1}$ weight \pm SD) in olive fruits from Arbequina and Picual olive trees (Olea europaea $\mathrm{L}$.) treated with MJ. Data from olive samples picked on days 3 and 6 after MJ application are included

\begin{tabular}{|c|c|c|c|c|}
\hline \multirow{2}{*}{$\begin{array}{c}\text { HYDROXYTYROSOL CONTENT } \\
\left(\mathbf{m g ~ k g}^{-1)}\right.\end{array}$} & \multicolumn{2}{|c|}{ ARBEQUINA } & \multicolumn{2}{c|}{ PICUAL } \\
\cline { 2 - 5 } & CONTROL & MJ TREATED & CONTROL & MJ TREATED \\
\hline DAY 3 & $146.92 \pm 1.23 \mathrm{Aa}$ & $169.49 \pm 1.95 \mathrm{Aa}$ & $161.92 \pm 1.72 \mathrm{Aa}$ & $271.03 \pm 1.63 \mathrm{Bb}$ \\
\hline DAY 6 & $229.72 \pm 0.98 \mathrm{Aa}$ & $150.76 \pm 2.01 \mathrm{~b}$ & $268.24 \pm 1.88 \mathrm{Aa}$ & n.d. \\
\hline
\end{tabular}

Data are presented as means $(n=3) \pm \mathrm{SD}$, where $n$ refers to three independent samples.

Different upper-case letters in the same row in control samples between cultivars indicate differences at $p<0.05$

Different lower-case letters in the same row between control and MJ treated samples within the same cultivar indicate differences at $p<0.05$.

Surprisingly, the exposition of Arbequina and Picual trees to MJ did not provide in general significantly $(p<0.05)$ higher oleuropein contents. In fact, oleuropein content on day 6 decreased from 220.45 to $159.15 \mathrm{mg} \mathrm{kg}^{-1}$ after MJ treatment in Arbequina. An exception was Picual olives picked on day 6 whose content increased from 348.00 to $576.38 \mathrm{mg} \mathrm{kg}^{-1}$ after pre-harvest treatment. Since PAL enzyme has been demonstrated to be activated by MJ [24,26], two possibilities are considered to explain the results on oleuropein content here found. Firstly, MJ might not have any effect on the oleuropein metabolism when pre-harvest applied. Alternatively, MJ might be activating PAL enzyme and, at the same time, inhibiting specific enzymes (ie, polyphenol oxidase, PPO) regulating the formation of oleuropein further in the phenylpropananoid pathway [26].

Table 4 represents the hydroxytyrosol content expressed as $\mathrm{mg} \mathrm{kg}^{-1}$ weight in olive fruits from Arbequina and Picual olive trees (Olea europaea L.) untreated-control and treated with MJ. Data obtained from samples picked on days 3 and 6 after MJ application are also shown. From Table 4, varietal differences in hydroxytyrosol contents in olive controls were not found. Values of 146.9 and $161.92 \mathrm{mg} \mathrm{kg}^{-1}$ were estimated on day 3 and 229.72 and $268.24 \mathrm{mg} \mathrm{kg}^{-1}$ on day 6 for Arbequina and Picual, respectively. Similarly to oleuropein, contents of hydroxytyrosol in controls on day 6 seemed to be higher than those on day 3 for both cultivars (compare Table 3 and 4). Concerning the MJ effect, the hydroxytyrosol content was not in general terms significantly $(p>0.05)$ increased by the pre-harvest MJ treatment. Actually, values on day 6 exhibited significant $(p<0.05)$ decreases of the hydroxytyrosol content as a result of MJ treatment (from 229.72 to 150.76 $\mathrm{mg} \mathrm{kg}^{-1}$ for Arbequina and from $268.24 \mathrm{mg} \mathrm{kg}^{-1}$ to even not detected for Picual). As an exception, Picual olives treated with MJ and picked on day 3 showed an increase of hydroxytyrosol content after MJ application (ie, 271.03 $\mathrm{mg} \mathrm{kg}-1$ in treated vs $161.92 \mathrm{mg} \mathrm{kg}^{-1}$ in controls). It is important to point out that hydroxytyrosol is a product derived from hydrolysis of oleuropein [27]. For this reason, similar evolution during the ripening process and similar response to $\mathrm{MJ}$ is somehow expected.

\subsection{Phenolic Acids}

Table 5 and Table 6 summarize the phenolic acid contents (expressed as $\mathrm{mg} \mathrm{kg}^{-1}$ weight \pm standard deviation) in olive fruits from MJ treated Arbequina and Picual olive trees (Olea europeae L.), respectively. Data from olive fruits picked on days 3 and 6 after MJ treatment are also represented in both tables.

As seen in Table 5 and Table 6 the contents of phenolic acids varied in a wide range in control olive fruits (ie, from 1.1 to $75.3 \mathrm{mg} \mathrm{kg}^{-1}$ ). These values are in the same range as data reported by other authors [20] as well as values found by ourselves in a previous study carried out in our laboratory [15]. However, it is worthy to note that Picual (see Table 6) exhibited lower contents than Arbequina (see Table 5). As also commented for TPC, varietal differences in phenolics are usual in plant-derived foods. In addition, differences in phenolic acid contents can also indicate a slightly different maturity stage between Arbequina and Picual. Interestingly, the phenolic acid contents in controls were similar on days 3 and 6 within each cultivar. For instance, gallic acid exhibited $10.5 \mathrm{mg} \mathrm{kg}^{-1}$ on day 3 and $13.2 \mathrm{mg} \mathrm{kg}^{1}$ on day 6 in untreated Arbequina olives (Table 5). Similarly, its content in untreated Picual olives was 2.1 and $3.1 \mathrm{mg} \mathrm{kg}^{-1}$ on days 3 and 6 , respectively.

As far as the MJ effect is concerned, Arbequina olives exhibited in general a significantly $(p<0.05)$ drop in the content of phenolic acids in treated olives whereas no MJ effect was determined on phenolic acid content in Picual olives. This finding is in disagreement with the increase in phenolic acid contents observed in an earlier study on the postharvest MJ effect [15]. The discrepancy between pre-harvest and post-harvest MJ effect in the phenolic acid content can be explained by differences in phenolic acid metabolism between the olive tree and the olive fruit. In 
other words, it is believed that PAL enzyme is affected differently depending on the moment in which the elicitor is applied. This theory explains results obtained for Picual cultivar since TPC decreased in pre-harvest MJ treated olives, which would indicate inhibitory effect of MJ on PAL when applied pre-harvest. However, this theory does not justify the increase of TPC in Arbequina treated samples, which reflects that PAL enzyme is always activated by exogenous MJ regardless the moment of its application.

In view of these results, varietal differences on preharvest MJ effect on olive phenolics are concluded. For Arbequina, MJ activates PAL, which in turn increases TPC, and at the same time, MJ inhibits other specific enzymes in the phenylpropanoid pathway responsible for bioformation of phenolic acids. For example, it is likely that MJ inhibits certain enzymes belonging PPOs, such as phenolasa and catechol-O-methyl transferasa, regulating the bioformation of caffeic acid and ferulic acid [28,29]. In contrast to Arbequina, MJ inhibits PAL activity in Picual olives resulting in a decrease of TPC. The inhibition of PAL leads to a decrease of cinnamic acid, which is a primary precursor in the pathway. This slows down the metabolism of the rest of phenolic compounds further in the pathway. On the other hand, it is interesting to note that phenolic acid content is not statistically changed in Picual by pre-harvest MJ. This involves that the specific enzymes regulating the last steps to the bioformation of phenolic acids are not inhibited by MJ. This is not the first time that varietal differences in the MJ treatment effects are observed. Bibliographic reports have proven that exogenous MJ effect can differ according to the variety in pak choi and plums [30,31]. In summary, the exogenous MJ application to olive tree affects differently to the phenolic composition in olive fruits according to the cultivar. In Arbequina, pre-harvest MJ results in increase of TPC and decrease of oleuropein, hydroxytyrosol and phenolic acids. From these results, increment of olive phenolics other than those studied in the present work (ie, tyrosol, cinnamic acid, luteolin...) as a consequence of the pre-harvest MJ application must be the reason for the increase of TPC. Contrary to Arbequina, the pre-harvest MJ application in Picual brought about the decline of TPC, oleuropein and hydroxytyrosol. No effect on phenolic acid content was however observed in Picual olives. On the other hand, it is convenient to highlight that the free radical scavenging activity of olive fruits increased with the pre-harvest MJ treatment for both Arbequina and Picual cultivars.

Concluding, the exposition of olive trees to MJ vapor in the right moment of the fruit ripening process provides olive fruits with better antioxidant properties. The effect of pre-harvest $\mathrm{MJ}$ in olives is cultivar dependent. That involves that the MJ influences varies with the olive cultivar and the specific phenolic compound studied. This is the first time that olive trees are elicited with the aim of improving the characteristics of olive fruits. The results found in the present study are promising, particularly, taking into account that the pre-harvest MJ treatment additionally protects the olive tree from diseases and plagues. The purpose now is to extent the study to extra olive phenolics and elicitation conditions to develop an effective and productive agronomic procedure to enhance the antioxidant properties in olive fruits.

Table 5. Phenolic acid contents (expressed as $\mathrm{mg} \mathrm{kg}^{-1}$ weight $\pm \mathrm{SD}$ ) in olive fruits from Arbequina olive trees (Olea europaea $\mathrm{L}$.) treated with MJ. Data from olive samples picked on days 3 and 6 after the MJ application are included

\begin{tabular}{lcccccc}
\hline SAMPLES & Gallic Acid & Chlorogenic Acid & Vanillic Acid & Caffeic Acid & $p$-Coumaric Acid & Ferulic Acid \\
\hline DAY 3 & & & & & & \\
\hline CONTROL & $10.5 \pm 0.2 \mathrm{a}$ & $28.6 \pm 0.1 \mathrm{a}$ & $46.5 \pm 0.1 \mathrm{a}$ & $6.9 \pm 0.1 \mathrm{a}$ & $5.6 \pm 0.1 \mathrm{a}$ & $75.3 \pm 0.2 \mathrm{a}$ \\
\hline MJ TREATED & $23.7 \pm 0.1 \mathrm{~b}$ & n.d. & $27.2 \pm 0.1 \mathrm{~b}$ & n.d. & $1.8 \pm 0.2 \mathrm{~b}$ & $15.2 \pm 0.2 \mathrm{~b}$ \\
\hline DAY 6 & & & & & \\
\hline CONTROL & $13.2 \pm 0.1 \mathrm{a}$ & $20.4 \pm 0.2 \mathrm{a}$ & $41.8 \pm 0.3 \mathrm{a}$ & $4.0 \pm 0.2 \mathrm{a}$ & $18.1 \pm 0.2 \mathrm{a}$ & $52.4 \pm 0.1 \mathrm{a}$ \\
\hline MJ TREATED & $18.1 \pm 0.01 \mathrm{~b}$ & $4.6 \pm 0.1 \mathrm{~b}$ & $10.3 \pm 0.2 \mathrm{~b}$ & $7.5 \pm 0.1 \mathrm{a}$ & $4.3 \pm 0.1 \mathrm{~b}$ & $20.1 \pm 0.3 \mathrm{~b}$ \\
\hline
\end{tabular}

Data are presented as means $(n=3) \pm \mathrm{SD}$, where $n$ refers to three independent samples.

Different lower-case letters in the same column between control and MJ treated samples within the same compound indicate differences at $p<0.05$

Table 6. Phenolic acid contents (expressed as $\mathrm{mg} \mathrm{kg}^{-1}$ weight \pm SD) in olive fruits from Picual olive trees (Olea europaea L.) treated with MJ. Data from olive samples picked on days 3 and 6 after MJ application are included

\begin{tabular}{|c|c|c|c|c|c|c|}
\hline SAMPLES & Gallic Acid & Chlorogenic Acid & VanillicAcid & Caffeic Acid & p-Coumaric Acid & Ferulic Acid \\
\hline \multicolumn{7}{|l|}{ DAY 3} \\
\hline CONTROL & $2.1 \pm 0.2 \mathrm{a}$ & n.d. & $1.3 \pm 0.1 \mathrm{a}$ & $1.1 \pm 0.1 \mathrm{a}$ & $1.8 \pm 0.3 \mathrm{a}$ & $1.1 \pm 0.1 \mathrm{a}$ \\
\hline MJ TREATED & $5.1 \pm 0.3 \mathrm{a}$ & $2.2 \pm 0.1 \mathrm{a}$ & $5.7 \pm 0.1 \mathrm{a}$ & $3.4 \pm 0.2 \mathrm{a}$ & $3.8 \pm 0.1 \mathrm{a}$ & $5.1 \pm 0.1 \mathrm{a}$ \\
\hline \multicolumn{7}{|l|}{ DAY 6} \\
\hline CONTROL & $3.1 \pm 0.1 \mathrm{a}$ & $1.2 \pm 0.1 \mathrm{a}$ & $4.2 \pm 0.2 \mathrm{a}$ & $2.8 \pm 0.3 \mathrm{a}$ & $1.7 \pm 0.1 \mathrm{a}$ & $1.8 \pm 0.2 \mathrm{a}$ \\
\hline MJ TREATED & $6.2 \pm 0.2 \mathrm{a}$ & $4.6 \pm 0.4 \mathrm{a}$ & $7.3 \pm 0.1 \mathrm{a}$ & $4.5 \pm 0.2 \mathrm{a}$ & $5.5 \pm 0.2 \mathrm{a}$ & $4.2 \pm 0.2 \mathrm{a}$ \\
\hline
\end{tabular}

Data are presented as means $(n=3) \pm \mathrm{SD}$, where $n$ refers to three independent samples.

Different lower-case letters in the same column between control and MJ treated samples within the same compound indicate differences at $p<0.05$. 


\section{Acknowledgments}

Authors thank the Comunidad Autónoma of Madrid (Spain) and European funding from FEDER program (research project S2013/ABI-3028, AVANSECAL-CM) for financial support. Dra. Gema Flores acknowledges CSIC for her JAE-Doc.

\section{References}

[1] Kiritsakis, A. (1998). Olive oil-Second Edition, From the tree to the table. Food and Nutrition. Press, Inc., Trumbull, Connecticut, USA. 1998:006611.

[2] Teissedre, P.L., Frankel, E.N., Waterhouse, A.L., Peleg, H. \& German, J.B. (1996). Inhibition of in vitro human LDL oxidation by phenolic antioxidants from grapes and wines. Journal of the Science of Food and Agriculture, 70, 55-61.

[3] Visioli, F., Poli, A. \& Galli, C. (2002). Antioxidant and other biological activities of phenols from olives and olive oil. Medicinal Research Reviews, 22, 65-75.

[4] Benavente-García, O., Castillo, J., Lorente, J., Ortuno, A. \& Del Río, J.A. (2000). Antioxidant activity of phenolics extracted from Olea europaea leaves. Food Chemistry, 68, 457-462.

[5] Pereira, A.P., Ferreira, I.C.F.R., Marcelino, F., Valentao, P., Andrade, P.B., Seabra, R., Estevinho, L., Bento, A. \& Pereira, J.A. (2007). Phenolic compound and antimicrobial activity of olive (Olea europaea L. cv Cobrancosa) leaves. Molecules, 12, 1153-1162.

[6] Micol, V., Caturla, N., Pérez-Fons, L., Mas, V., Pérez, L. \& Estepa, A. (2005). The olive leaf extract exhibits antiviral activity against viral haemorrhagic septicaemia rhabdovirus (VHSV). Antiviral Research, 66, 129-136.

[7] Visioli, F., Bellosta, S. \& Galli, C. (1998). Oleuropein, the bitter principles of olives, enhances nitric oxide production by mouse macrophages. Life Science, 62, 541-546.

[8] Andreadou, I., Illiodromitis, E.K., Mikros, E., Constantinou, M., Agalias, A., Magiatis, P., Skaltsounis, A.L., Kamber, E., TsantiliKakoulidou, A. \& Kremastinos, D.T. (2006). The olive constituent oleuropein exhibits anti-ischemic, antioxidative, and hypolipidemic effects in anesthetized rabbits. Journal of Nutrition, 136, 2213-2219.

[9] Jemai, H., Bouaziz, M., Fki, I., El Feki, A. \& Sayadi, S. (2008). Hypolipidimic and antioxidant activities of oleuropein and its hydrolysis derivative-rich extracts from ChemLali olive leaves. Chemico-Biological Interactions, 176, 88-98.

[10] Morton, I.W., Caccetta, R.A.A., Puddey, I.B. \& Croft, K.D. (2000). Chemistry and biological effects of dietary phenolic compounds: relevance to disease. Clinical and Experimental Pharmacology and Physiology, 27,152-159.

[11] Johnston, K.L., Clifford, M.N. \& Morgan, L.M. (2003). Coffee acutely modifies gastrointestinal hormone secretion and glucose tolerance in humans: glycemic effects of chlorogenic acid and caffeine. The American Journal of Clinical Nutrition, 78, 728-733.

[12] de la Peña Moreno, F., Monagas, M., Blanch, G.P., Bartolomé, B. \& Ruiz del Castillo, M.L. (2010). Enhancement of anthocyanins and selected aroma compounds in strawberry fruits through methyl jasmonate vapor treatment. European Food Research and Technology, 230, 989-999.

[13] Ruiz del Castillo, M.L., Flores, G. \& Blanch, G.P. (2010). Exogenous methyl jasmonate diminishes the formation of lipid-derived compounds in boiled potatoes (Solanum tuberosum L.). Journal of the Science of Food and Agriculture, 90, 2263-2267.

[14] Flores, G. \& Ruiz del Castillo, M.L. (2014). Influence of preharvest and post-harvest methyl jasmonate treatments on flavonoid content and metabolomic enzymes in red raspberry. Postharvest Biology \& Technology, 97, 77-82.
[15] Flores, G., Blanch, G.P. \& Ruiz del Castillo, M.L. (2017). Effect of postharvest methyl jasmonate treatment on fatty acid composition and phenolic acid content in olive fruits during storage. Journal of the Science of Food and Agriculture, 97, 2767-2772.

[16] González-Aguilar, G.A., Fortiz, J., Cruz, R., Baez, R. \& Wang, C.Y. (2000). Methyl jasmonate reduces chilling injury and maintains postharvest quality of mango fruit. Journal of Agricultural and Food Chemistry, 48, 515-519.

[17] Vinha, A.F., Ferreres, F., Silva, B.M., Valentao, P., Gongalves, A., Pereira, J.A., Oliveria, M.B., Seabre, R.M. \& Andrade, P.B. (2005). Phenolic profiles of Portuguese olive fruits (Olea europea L.): Influence of cultivar and geographical origin. Food Chemistry, $89,561-568$.

[18] Singleton, V.L. \& Rossi, J.A. (1965). Colorimetry of total phenolics with phosphomolybdic-phosphotungstic acid reagents". American Journal of Enology and Viticulture, 16, 144-158.

[19] Smith, R.C., Reeves, J.C., Dage, R.C. \& Schnettler, R.A. (1987). Antioxidant properties of 2-imidazolones and 2-imidazolthiones. Biochemical Pharmacology, 36, 1457-1460.

[20] Arslan, D. \& Özcan, M.M. (2011). Phenolic profile and antioxidant activity of olive fruits of the Turkish variety "Sarrulak" from different locations. Grasas y Aceites, 62, 453-461.

[21] Vacca, V., Fenu, P., Franco, M.A. \& Sferlazzo, G. (1993). Primo approccio alla caratterizzazione dei composti fenolici di oli vergini di oliva della Sardegna: elaborazioni statistiche multivariate dei risultati in HPLC. Rivista Italian Dell Sostanze Grasse, 70, 595-599.

[22] Ryan, D. \& Robards, K. (1998). Phenolic compounds in olives. Analyst, 123, 31R-44R.

[23] Kim, H.J., Chen, F., Wang, X. \& Choi, J-H. (2006). Effect of methyl jasmonate on phenolics isothiocyanate and metabolic enzymes in radish sprout (Raphanus Sativus L.). Journal of Agricultural and Food Chemistry, 54, 7263-7269.

[24] Flores, G., de la Peña Moreno, F., Blanch, G.P. \& Ruiz del Castillo, M.L. (2014). Phenylalanine ammonia-lyase, flavanone $3 \beta$-hydroxylase and flavonol synthase enzyme activity by a new in vitro assay method in berry fruits. Food Chemistry, 153, 130-133.

[25] Braicu, C., Pilecki, V., Balacescu, O., Irimie, A. \& Berindan Neagoe, I. (2011). The relationships between biological activities and structure of flavan-3-ols. Intermolecular Journal of Molecular Sciences, 12, 9342-9353.

[26] Ortega-García, F., Blanco, S., Peinado, M.A. \& Peragón, J. (2008) Polyphenol oxidase and its relationship with oleuropein concentration in fruits and leaves of olive (Olea europaea L.) cv "Picual" trees during fruit ripening. Tree Physiology, 28, 45-54.

[27] Granados-Principal, S., Quiles, J.L., Ramirez-Tortosa, C.L., Sanchez-Rovira, P. \& Ramirez-Tortosa, M.C. (2010). Hydroxytyrosol: From laboratory investigations to future clinical trials. Nutrition Reviews, 68, 191-206.

[28] Piquemal, J., Chamayou, S., Nadaud, I., Beckert, M., Barriére, Y., Mila, I., Lapierre, C., Rigau, J., Puigdomenech, P., Jauneau, A., Digonnet, C., Boudet, A-M., Goffner, D. \& Pichon, M. (2002). Down-regulation of caffeic acid O-methyltransferase in maize revisited using a transgenic approach. Plant Physiology, 130, 1675-1685.

[29] Yoruk, R. \& Marshall, M.R. (2003). Physicochemical properties and function of plant polyphenol oxidase: a review. Journal of Food Biochemistry, 27, 361-422.

[30] Martínez-Esplá, A., Zapata, P.J., Castillo, S., Guillén, F., Martínez-Romero, D., Valero, D. \& Serrano, M. (2014). Pre-harvest application of methyl jasmonate in two plum cultivars. 1. Improvement of fruit growth and quality attributes at harvest. Postharvest Biology \& Technology, 98, 98-105.

[31] Kim, M.J., Chiu, Y-Ch., Kim, N.K., Park, H.M., Lee, Ch. H., Juvik, J.A. \& Ku, K-M. (2017). Cultivar-Specific Changes in Primary and Secondary Metabolites in Pak Choi (Brassica Rapa, Chinensis Group) by Methyl Jasmonate. International Journal of Molecular Sciences, 18, 1004. 